\title{
Centralized Airflow Control to Reduce Output Power Variation in a Complex OWC Ocean Energy Network
}

\author{
Sunil Kumar Mishra $\mathbb{D}^{1},{ }^{1}$ Bhargav Appasani, ${ }^{1}$ Amitkumar Vidyakant Jha, ${ }^{1}$ \\ Izaskun Garrido $\mathbb{D}^{2}{ }^{2}$ and Aitor J. Garrido ${ }^{2}$ \\ ${ }^{1}$ School of Electronics Engineering, Kalinga Institute of Industrial Technology, Bhubaneswar 751024, India \\ ${ }^{2}$ Automatic Control Group (ACG), Institute of Research and Development of Processes (IIDP), \\ University of the Basque Country-UPV/EHU, Department of Automatic Control and Systems Engineering, \\ Faculty of Engineering of Bilbao, Po Rafael Moreno No. 3 (48013), Bilbao, Spain \\ Correspondence should be addressed to Sunil Kumar Mishra; sunil.mishrafet@kiit.ac.in
}

Received 13 June 2020; Accepted 1 August 2020; Published 18 August 2020

Guest Editor: Ramon Costa Castelló

Copyright (c) 2020 Sunil Kumar Mishra et al. This is an open access article distributed under the Creative Commons Attribution License, which permits unrestricted use, distribution, and reproduction in any medium, provided the original work is properly cited.

\begin{abstract}
A centralized airflow control scheme for a complex ocean energy network (OEN) is proposed in this paper to reduce the output power variation (OPV). The OEN is an integrated network of multiple oscillating water columns (OWCs) that are located at different geographical sites connected to a common electrical grid. The complexity of the OWC-OEN increases manifolds due to the integration of several OWCs and design of controllers become very challenging task. So, the centralized airflow control scheme is designed in two stages. In control stage-1, a proportional-integral- (PI-) type controller is designed to provide a common reference command to control stage-2. In control stage-2, the antiwindup PID controllers are implemented for the airflow control of all the OWCs simultaneously. In order to tune the large number of control parameters of this complex system, a fitness function based on integral squared error (ISE) is minimized using the widely adopted particle swarm optimization (PSO) technique. Next, the simulation results were obtained with random wave profiles created using the Joint North Sea Wave Project (JONSWAP) irregular wave model. The OPV of the proposed OWC-OEN was reduced significantly as compared to the individual OWC. It was further observed that the OPV of the proposed scheme was lower than that achieved with uncontrolled and MPPT controlled OWC-OEN. The effect of communication delay on the OPV of the proposed OWC-OEN scheme was also investigated with the proposed controller, which was found to be robust for a delay up to $100 \mathrm{~ms}$.
\end{abstract}

\section{Introduction}

Many countries around the world with a long coastal zone have been actively exploring ocean waves as an alternate energy source over the past five decades [1-9]. European countries have taken a leading role in the research and development of this sector [1-3]. Research in ocean wave energy also started later in countries such as Australia, Brazil, China, India, Indonesia, Japan, Korea, Maldives, Taiwan, and the United States [4-9]. The majority of the ocean wave power plants across the globe use oscillating water column technology (OWC) [10-12]. With a lot of consistent efforts by the research community, this technology has matured enough in recent years. However, due to high output power variation (OPV), hurdles remain in its grid integration. The OPV is defined as the difference between the maximum and minimum power generated from the OWC plant. Reducing OPV is one of the major challenges of OWC. It requires advanced control systems to minimize OPV as much as possible.

1.1. Literature Review of OWC Control. Over the years, the OWC has been tried and tested by several control schemes [13-41]. The initial stage of the controller design for OWC was primarily on phase control [13] and latching control 
[14]. Subsequently, in [15], a controller by swinging rotorblades of the wells turbine was proposed to optimize OWC performance. A reactive controller for a fixed two-dimensional OWC was developed in [16]. In [17], an airflow control scheme for OWC-Wells turbine using throttle and bypass valves was discussed. Justino and Falcao [18] presented the rotational speed controller for OWC-Wells turbine and electrical generator. An approach for obtaining the maximum output power from the OWC plant was described in [19]. In [20], a power electronic controller was designed for an OWC system with an induction generatorWells turbine. In [21], the rotor side controller with constant frequency and variable speed operation of OWC was presented.

After the establishment of the OWC plant at the Mutriku harbor in Spain, a neural network network-based controller for OWC module was proposed in [22], which was supposed to change the external rotor resistance values to vary the induction generator slip. The PID-based control approaches for OWC plants were developed in [23] for airflow and rotor speed control. In [24], the control schemes proposed in [23] were validated on the experimental module. Neural network-based optimum speed reference for PI-based rotational speed control of the OWC system was proposed in [25]. In [26], an analysis was executed on fault-ride-through capability of OWC stations. It was equipped with doubly fed induction generator (DFIG) and an airflow-based controller. In [27], a sliding-mode control of OWC plants for maximizing output power of DFIG was designed.

In recent years, many advanced control techniques for OWC airflow as well as turbine rotor speed control techniques have been developed. In [28], a control technique was developed for efficiency enhancement of Wells turbineOWC devices. A comprehensive survey of electrical controllers for ocean energy devices including OWC was discussed in [29]. In [30], the controller for merging local energy storage with OWC was proposed. A rotational speed optimization approach was applied in [31] to attain maximum power point tracking (MPPT) of OWC. In [32] as well, a latching control scheme was developed for MMPT of a floating OWC wave energy converter. An optimal speed controller based on the fuzzy-backstepping method was designed in [33]. Three Lyapunov-based nonlinear controllers were proposed in [34] for OWC plant emulation, rotational speed control, and DC link voltage control of DFIG's grid side converter (GSC), respectively. The flow controller was designed in [35] for Wells turbines for harnessing maximum wave power using OWC. An eventtriggered controller for the OWC energy plant was presented in [36] wherein the main objective was to minimize control updates when the controller and plant interact with the other via communication channel. In [37], a fuzzy gain scheduled and PI-type airflow controller for an OWC, which was an advanced version of the airflow controller, were presented earlier in [23, 24]. Recently, some artificial intelligence-based airflow controller techniques have been proposed [38-40]. A self-adaptive global best harmony search algorithm-based airflow control of OWC was proposed by [38] wherein four variants of the harmony search algorithm were implemented and tested to optimize the control design of the PID controller in the airflow control scheme. In [39], another approach for airflow control was proposed which utilized symmetry-breaking concept to design the controller. Furthermore, an artificial neural network-based airflow controller was designed using surface elevation measurements [40]. This study considered real measured wave input data and generated power of the NEREIDA wave power plant. For more details on the control of OWC plants, please refer [41].

1.2. Main Contributions. In the above-discussed control schemes, the output power of OWC can be maximized successfully using rotor speed regulation wherein actual rotor speed follows optimum reference speed. Also, output power can be controlled to some extent by using an air flow controller but the high OPV is still a huge challenge in OWC. To the best of the authors' knowledge this issue has not been addressed so far by forming a large network of OWC. The randomness in ocean wave input at the OWC plant is a serious concern. If the multiple OWCs operating at different geographical locations are integrated, then the same randomness of ocean waves might be helpful in reducing OPV as compared to that of an isolated OWC. The OPV can also be reduced further by suitably designing a centralized airflow controller for regulating the airflow of OWC chambers situated at different geographical sites. However, the design complexity of the controller for this system is increased.

Hence, in this paper, the issue of high OPV has been addressed by integrating multiple OWC sites located at different geographical locations. Hereafter, the integrated OWC sites would be referred to as OWC ocean energy network (OEN). Now, two control schemes would be designed for OWC-OEN: (i) localized MPPT control and (ii) centralized airflow control for reducing OPV. The localized MPPT control law would again be consisting of two sections: (i) an algorithm for optimum reference speed calculation and (ii) backstepping controller for rotor speed regulation. The centralized airflow controller would provide common commands to all individual OWC sites. The centralized airflow controller is a two stage control scheme. In control stage-1, a proportional-integral- (PI-) type controller is designed to provide a common reference command to control stage- 2 . In control stage-2, the antiwind PID controllers are implemented for the airflow control of all OWC sites. Suppose, there are $N$ number of OWC sites included in OWC-OEN, two unknown parameters of the PI controller in control stage-1, and three unknown PID parameters of each OWC site in control stage-2. Then, the $3 N+2$ number of controller design parameters would be required to be properly selected so that OPV of OWC-OEN can be reduced considerably. In order to tune the $3 N+2$ parameters, an integral squared error- (ISE-) type fitness function is defined. The fitness function is minimized with the help of particle swarm optimization (PSO) algorithm [42-45]. The PSO method is very instrumental in optimizing the parameters of complex systems. 
The numerical simulations were performed on MATLAB $^{\circledR}$ platform using Joint North Sea Wave Project (JONSWAP) irregular wave model [46]. Several JONSWAP wave profiles are generated randomly using Wave Analysis for Fatigue and Oceanography (WAFO) MATLAB ${ }^{\circledR}$ toolbox [47]. The performance of an arbitrarily selected OWC site has been analyzed for relevant OWC parameters such as rotor speed, control signal, Wells turbine flow coefficient, and DFIG output power of controlled/uncontrolled OWC. The performance of the proposed control system of OWCOEN has been validated using a newly introduced performance index referred to as OPV index. The OPV index of all OWC sites, uncontrolled OWC-OEN, localized MPPT control of OWC-OEN, and centralized airflow control of OWC-OEN are compared. Also, the effect of transmission delay has been studied by introducing the delay in the OWCOEN.

The rest of the paper would be discussed with following sections. Wave-to-wire modelling and control of an individual OWC site in Section 2; design of OWC-OEN and centralized airflow controller in Section 3; discussion on simulation results in Section 4 , and concluding remarks and future scopes in Section 5.

\section{Wave-to-Wire Modelling and Control of an Individual OWC Plant}

Figure 1 displays the schematic representation of OWC plant configuration and its control schemes. As shown in Figure 1, the OWC consists of a chamber, turbine, electrical generator, and controller [34]. The waves of the sea hit the front of the chamber, causing an increase and fall in the water. In the chamber, the air moves back and forth to a circular cavity above the chamber. Thus, the Wells turbine generator machine, which is mounted in the cavity, is operated by twoway air flow [16].

The controllers are certainly an essential component of OWC systems. There are mainly three control configurations of OWC plants as uncontrolled, MPPT control, and airflow control. In uncontrolled OWC plant configuration, OWC operates without any control action. The output power generated in uncontrolled condition directly depends upon the sea wave input and the characteristics of turbine generator. In case of MPPT control, the rotor speed is regulated as per the reference rotor speed wherein the reference speed depends upon the sea wave input to the plant. This mechanism helps in extracting maximum output power from the OWC plant. Finally, in airflow control of the OWC plant, the control valve is used to restrict the airflow inside the OWC chamber in such a manner that desired electrical power is generated. Next, we will discuss OWC device modelling and its MPPT control.

2.1. Ocean Waves. Most OWC experiments have chosen regular types of ocean waves for OWC output evaluation, but real sea wave actions and irregularities are highly unpredictable. In order to deal with this problem, researchers have therefore developed a number of practical sea wave

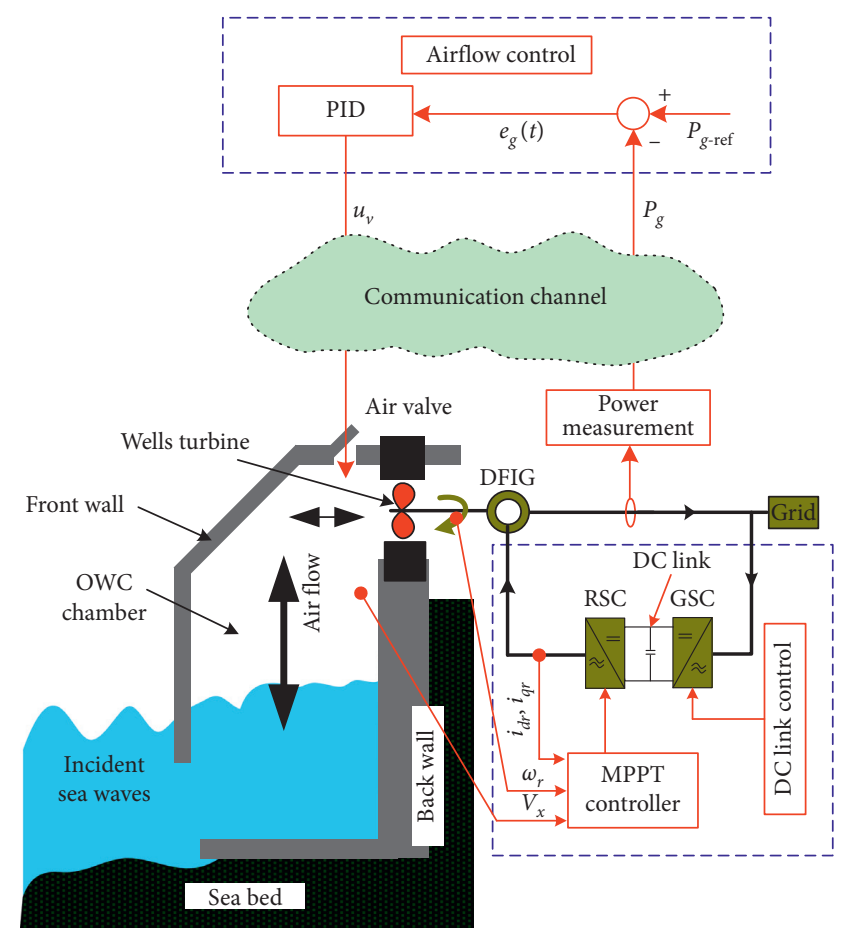

FIGURE 1: Different configurations of an individual OWC plant and its control schemes.

models $[46,47]$. In this analysis, the irregular JONSWAP wave pattern is used to test the efficiency of the proposed controls. It is one of the commonly used models for marine technical research.

The characterization parameters for JONSWAP are significant wave height $\left(H_{m 0}\right)$, peak wave period $\left(T_{p}\right)$, and peakedness parameter $(\gamma)$. The JONSWAP model gives best characterization in the range $3.6 \sqrt{H_{m o}}<T_{p}<5 \sqrt{H_{m o}}$ and $1<\gamma<7$ [34]. The JONSWAP wave spectrum for the values of $H_{m 0}, T_{p}$, and $\gamma$ given in Table 1 is shown in Figure 2 wherein the highest frequency component is around $0.5 \mathrm{rad} / \mathrm{s}$.

2.2. OWC Chamber Model. The OWC consists of a closed room with four side walls with openings at top and bottom (Figure 1). It is partly immersed in water and waves hit the lower section of the chamber. As the water level rises and falls, a two-way air flow is produced. The water level change is also referred to as the wave height. The air velocity mathematical definition is provided by [36]

$$
V_{x}=\left(\frac{A_{\text {OWC }}}{A_{\text {duct }}+A_{\text {valve }}}\right) \cdot \frac{\partial h(t)}{\partial t} .
$$

The air velocity definition established by (1) is the input for the Wells turbine. Here, it has been assumed that $A_{\text {valve }}=u_{v}$. It means that the control valve has unity transfer function for a simplified case or does not have any actuator delay.

2.3. Wells Turbine Model. The Wells turbine $[24,48]$ is a turbine of unique features and can be seen in Figure 3. This rotates in the same direction by input of two-way air flow, 
TABLE 1: JONSWAP wave model, OWC chamber, Wells turbine, and DFIG parameters.

JONSWAP wave model:

$H_{m 0}=7 \mathrm{~m} ; T_{p}=11 \mathrm{~s} ; \gamma=2.3853$

DFIG:

Chamber:

$A_{\text {OWC }}=7.5 \mathrm{~m}^{2} ; A_{\text {duct }}=1.18 \mathrm{~m}^{2} ; A_{\text {valve }}=1 \mathrm{~m}^{2}$

Wells turbine:

$n=8 ; k_{t}=0.7079 ; b=0.4 \mathrm{~m} ; r=0.3643 \mathrm{~m} ; l=0.38 \mathrm{~m}$

$p=4 ; R_{s}=0.0181 ; R_{r}=0.0334 ; L_{s}=7.543 ; L_{r}=7.573 ; L_{m}=7.413 ; V_{s}=390 / \sqrt{3} \mathrm{~V} ;$

$\omega_{e}=100 \pi \mathrm{rad} / \mathrm{s} ; F=0.02 ; J=50 ; P_{g-\text { rated }}=100.0 \mathrm{~kW}$ (individual OWC site);

$P_{\text {gtotal-rated }}=2.0 \mathrm{MW}(\mathrm{OWC}-\mathrm{OEN})$

Initial conditions:

$\omega_{r 0}=100 \mathrm{rad} / \mathrm{s} ; \psi_{d s} \quad{ }_{0}=\psi_{s}=V_{s} / \omega_{e}=0.7167 \mathrm{~Wb}$;

$\psi_{q s 0}=\psi_{d r 0}=\psi_{q r 0}=0 \mathrm{~Wb}$

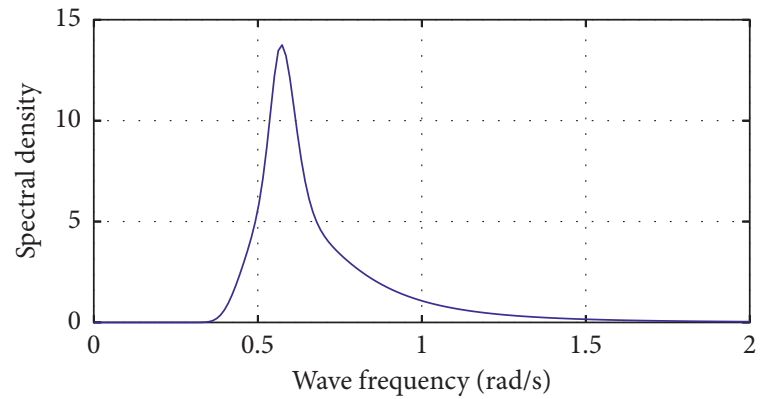

FIgURE 2: JONSWAP wave spectrum.

but has a restriction of stalling. The power output falls considerably because of the stalling. A control unit is therefore necessary to prevent the stall.

Turbine torque description is given as follows [24]:

$$
T_{t}=f_{t}(\varphi) \cdot V_{x}^{2}
$$

where $f_{t}(\phi)$ is stated as follows:

$$
f_{t}(\varphi)=C_{t} \cdot k_{t} \cdot r \cdot\left(1+\varphi^{-2}\right),
$$

where $C_{t}$ is the Wells turbine torque coefficient and depends on $\phi$ as displayed in Figure 3. The $\phi$ is given by

$$
\varphi=V_{x} \cdot\left(r \omega_{r}\right)^{-1} \text {. }
$$

As shown in Figure $4, \phi \leq \phi_{\text {th }}=0.3$ provides the highest torque coefficient to deliver the maximum torque and therefore the maximum output power.

The turbine is attached to a DFIG. The coupling function of the turbine generator can thus be expressed as follows:

$$
\frac{\mathrm{d} \omega_{r}}{\mathrm{~d} t}=\frac{1}{J}\left(T_{t}-F \cdot \omega_{r}-T_{e}\right),
$$

where $\omega_{r}$ has initial condition $\omega_{r 0}$.

2.4. DFIG Dynamics. This analysis considered a directquadrature $(d q)$ dynamic DFIG model. The $d q$ dynamic model's benefit is that every three-phase voltage or current in the stationary frame can be interpreted as DC voltage or current in a synchronous revolving frame $[15,16]$. The state equations of $d q$-axis stator and rotor flux states of DFIG are given as follows [20]:

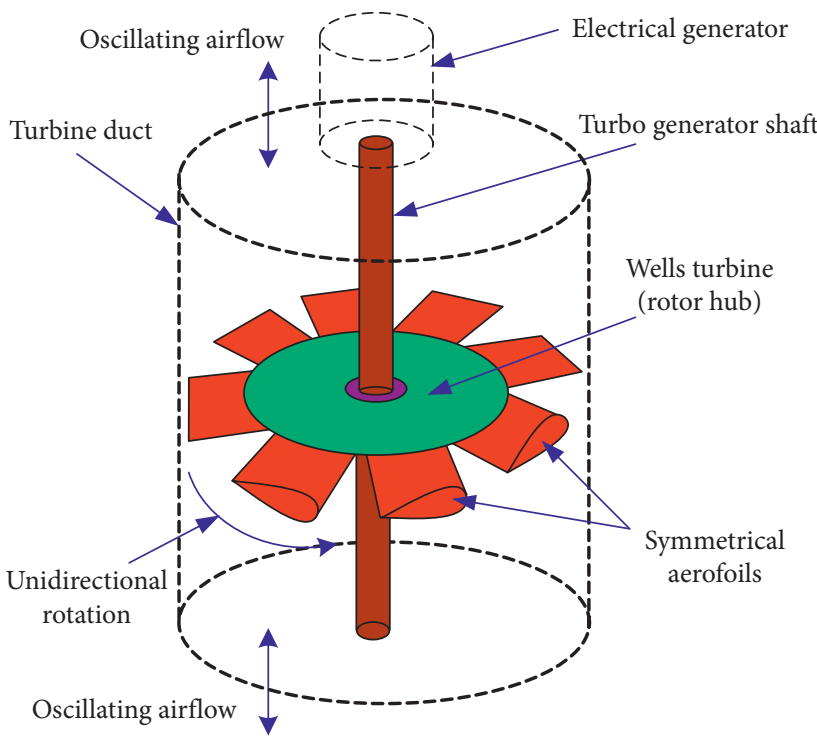

FIgURE 3: Wells turbine schematic diagram.

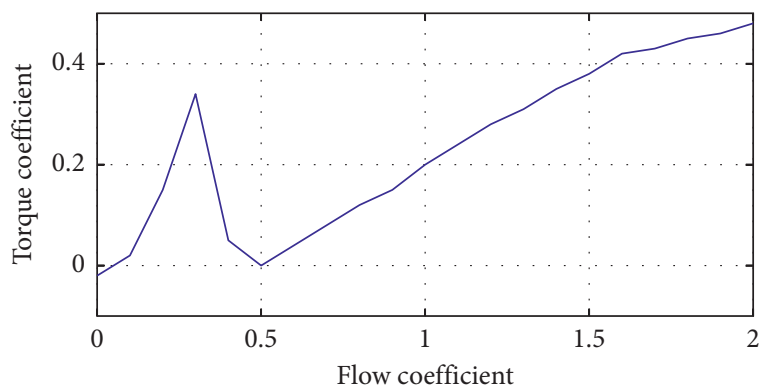

Figure 4: Turbine characteristics.

$$
\begin{aligned}
& \frac{\mathrm{d} \psi_{d s}}{\mathrm{~d} t}=-\frac{R_{s} L_{r}}{K} \psi_{d s}+\omega_{e} \psi_{q s}+\frac{R_{s} L_{m}}{K} \psi_{d r}+v_{d s}, \\
& \frac{\mathrm{d} \psi_{q s}}{\mathrm{~d} t}=-\omega_{e} \psi_{d s}-\frac{R_{s} L_{r}}{K} \psi_{q s}++\frac{R_{s} L_{m}}{K} \psi_{q r}+v_{q s}, \\
& \frac{\mathrm{d} \psi_{d r}}{\mathrm{~d} t}=\frac{R_{r} L_{m}}{K} \psi_{d s}-\frac{R_{r} L_{s}}{K} \psi_{d r}-\left(\omega_{r}-\omega_{e}\right) \psi_{q r}+v_{d r}, \\
& \frac{\mathrm{d} \psi_{q r}}{\mathrm{~d} t}=\frac{R_{r} L_{m}}{K} \psi_{q s}+\left(\omega_{r}-\omega_{e}\right) \psi_{d r}+v_{q r},
\end{aligned}
$$

where $K=L_{s} L_{r}-L_{m}^{2} \cdot \psi_{d s}, \psi_{q s}, \psi_{d r}$, and $\psi_{q r}$ are stator and rotor $d q$ flux quantities. $R_{s}$ and $R_{r}$ are stator and rotor 
resistances, whereas $L_{s}, L_{r}$, and $L_{m}$ are the stator, rotor, and mutual inductances. $\omega_{e}$ is the stator supply frequency, $v_{d s}, v_{q s}, v_{d r}$, and $v_{q r}$ are stator and rotor $d q$ voltages. The flux states $\psi_{d s}, \psi_{q s}, \psi_{d r}$, and $\psi_{q r}$ are subjected to initial conditions $\psi_{d s 0}, \psi_{q s 0}, \psi_{d r 0}$, and $\psi_{q r 0}$, respectively. The electromagnetic torque and output power expressions are

$$
\begin{aligned}
& T_{e}=-M\left(\psi_{q s} \psi_{d r}-\psi_{d s} \psi_{q r}\right), \\
& P_{g}=T_{e} \omega_{r},
\end{aligned}
$$

where $M=-(3 / 2)(p / 2)\left(L_{m} / K\right)$ and $p$ is number of poles of DFIG.

The $d q$-axis voltages of the rotor are converted into $a b c$ axis voltages of the rotor. Furthermore, the $a b c$-axis voltage signals will be sent to pulse width modulation (PWM), the gate pulses of which will be sent to DFIG's DC/AC rotor side converter (RSC) $[11,12,23]$.

\subsection{Localized MPPT Control of an Individual OWC Plant.} The airflow control and rotor speed regulation blocks, as shown in Figure 1, are the two most important controllers for OWC control. As mentioned earlier, the rotor speed regulator is considered for localized MPPT control of the OWC plant. The MPPT control can be achieved using linear or nonlinear controller in which the actual rotor speed is forced to track an optimum speed reference $[24,25,27,31,33,34,36]$. The optimum reference speed calculation algorithm is designed in such a manner that it would always lead to maximum output power. In this work, a backstepping-type rotor speed controller and optimum reference speed calculation algorithm have been designed using the approach described in [36].

The optimum reference speed calculation algorithm [36] is presented next. It is calculated using air velocity information in the following steps:

(i) Step 1: calculate the value of $V_{x}$ using (1).

(ii) Step 2: calculate peak values of $V_{x}$ as follows:

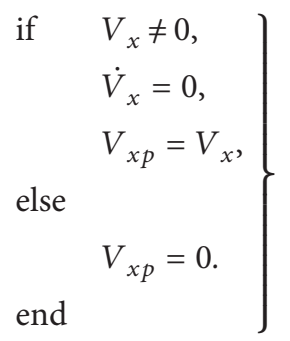

(iii) Step 3: pass $V_{x p}$ through zero-order-hold ( $\left.\mathrm{ZOH}\right)$ as follows:

$$
\bar{V}_{x p}=\mathrm{ZOH}\left(V_{x p}\right)
$$

(iv) Step 4: for threshold value of the flow coefficient, $\varphi_{t h}=0.3$, calculate the reference speed using (4) as follows:

$$
\omega_{r e f}=\bar{V}_{x p}\left(r \varphi_{t h}\right)^{-1}
$$

(v) Step 5: calculate $\omega_{1 d}$ by limiting the minimum and maximum values of $\omega_{\text {ref }}$ as follows:

$$
\left.\begin{array}{ll}
\text { if } & \omega_{r e f} \leq \omega_{e}, \\
& \omega_{1 d}=\omega_{e}, \\
\text { elseif } & \omega_{r e f} \geq \omega_{e}, \\
& \omega_{1 d}=\omega_{r p}, \\
\text { else } & \\
& \omega_{1 d}=\omega_{r e f}, \\
\text { end } &
\end{array}\right\}
$$

where $\omega_{e}$ is the minimum value of $\omega_{1 d}$ and $\omega_{r p}$ is the maximum value of $\omega_{1 d}$.

(vi) Step 6: in order to avoid any sudden change in the reference value, pass $\omega_{1 d}$ through a low-pass filter. The new reference value is calculated as follows:

$$
z_{1 d}=h_{f} \otimes \omega_{1 d} .
$$

The frequency domain representation of $h_{f}$ is given as follows:

$$
H_{f}(s)=\frac{1}{1+0.1 s} .
$$

As a result, the $z_{1 d}$ is the optimum reference speed to be used for proposed controllers. Next, the backstepping-type rotor speed regulator would be designed to force the actual rotor speed to track the optimum reference speed $z_{1 d}$.

The state space model from [36] is given below:

$$
\begin{aligned}
& \dot{z}_{1}=k_{1} z_{1}+k_{2} z_{2}+D, \\
& \dot{z}_{2}=k_{3}\left(z_{1}-\omega_{e}\right)+k_{4} z_{2}+u_{r},
\end{aligned}
$$

where $\quad k_{1}=-(F / J) ; \quad k_{2}=-(M / J) ; \quad k_{3}=\left(L_{r} / L_{m}\right) \psi_{s}$; $k_{4}=-\left(R_{r} L_{s} / K\right) ; \quad u_{r}=$ control signal $=v_{q r} ; \quad D=\left(T_{t} / J\right) ;$ $z_{1}=\omega_{r} ;$ and $z_{2}=\psi_{q r}$.

Furthermore, simplifying the above equation, we have

$$
\begin{aligned}
& \dot{z}_{1}=f_{1}\left(z_{1}, D\right)+k_{2} z_{2}, \\
& \dot{z}_{2}=f_{2}\left(z_{1}, z_{2}\right)+u_{r},
\end{aligned}
$$

where $f_{1}\left(z_{1}, D\right)=k_{1} z_{1}+D$ and $f_{2}\left(z_{1}, z_{2}\right)=k_{3}\left(z_{1}-\omega_{e}\right)+$ $k_{4} z_{2}$.

A step by step design approach is applied for the backstepping controller. For a second-order system expressed by (15) and (16), the controller is designed in two 
stages. First, a virtual controller, $z_{2 d}$, is to be designed. Then, $z_{2 d}$ would be used for designing final control law $u_{r}$.

For designing the virtual control law, $z_{2 d}$, let us choose the error component as follows:

$$
\widetilde{z}_{1}=z_{1 d}-z_{1} \text {. }
$$

Next, the first order derivative of (17) is written as follows:

$$
\dot{\widetilde{z}}_{1}=\dot{z}_{1 d}-\dot{z}_{1}=\dot{z}_{1 d}-f_{1}\left(z_{1}, D\right)-k_{2} z_{2} .
$$

Furthermore, by adding and subtracting $k_{2} z_{2 d}$ term, (18) becomes

$$
\dot{\vec{z}}_{1}=\dot{z}_{1 d}-f_{1}\left(z_{1}, D\right)-k_{2} z_{2}+k_{2} z_{2 d}-k_{2} z_{2 d} .
$$

The virtual control law $z_{2}{ }_{d}$ is chosen as follows:

$$
z_{2 d}=k_{2}^{-1}\left(\dot{z}_{1 d}-f_{1}\left(z_{1}, D\right)+\sigma_{1} \widetilde{z}_{1}\right),
$$

where $\sigma_{1}>0$.

Define

$$
\tilde{z}_{2}=z_{2 d}-z_{2}
$$

Substituting (20) and (21), (19) can be expressed as follows:

$$
\dot{\vec{z}}_{1}=-\sigma_{1} \widetilde{z}_{1}+k_{2} \widetilde{z}_{2}
$$

Next, the derivative of (21) is given by

$$
\dot{\vec{z}}_{2}=\dot{z}_{2 d}-\dot{z}_{2}=\dot{z}_{2 d}-f_{2}\left(z_{1}, z_{2}\right)-u_{r}
$$

For designing the control law which ensures the closed loop stability of systems (15) and (16), a Lyapunov function candidate, $V_{l p f}$, is chosen as follows:

$$
V_{l p f}=\frac{1}{2}\left(\widetilde{z}_{1}^{2}+\widetilde{z}_{2}^{2}\right) \text {. }
$$

The first order time derivative of (23) is expressed as follows:

$$
\begin{aligned}
& \dot{V}_{l p f}=\widetilde{z}_{1} \dot{\tilde{z}}_{1}+\widetilde{z}_{2} \dot{\tilde{z}}_{2}, \\
\Rightarrow & \dot{V}_{l p f}=\widetilde{z}_{1}\left(-\sigma_{1} \widetilde{z}_{1}+k_{2} \widetilde{z}_{2}\right)+\widetilde{z}_{2}\left(\dot{z}_{2 d}-f_{2}\left(z_{1}, z_{2}\right)-u_{r}\right), \\
\Rightarrow & \dot{V}_{l p f}=-\sigma_{1} \widetilde{z}_{1}^{2}+\widetilde{z}_{2}\left\{\dot{z}_{2 d}-f_{2}\left(z_{1}, z_{2}\right)+k_{2} \widetilde{z}_{1}-u_{r}\right\} .
\end{aligned}
$$

The control law $u_{r}$

$$
u_{r}=\dot{z}_{2 d}-f_{2}\left(z_{1}, z_{2}\right)+k_{2} \tilde{z}_{1}+\sigma_{2} \widetilde{z}_{2},
$$

gives

$$
\dot{V}_{l p f}=-\sigma_{1} \widetilde{z}_{1}^{2}-\sigma_{2} \widetilde{z}_{2}^{2} \leq 0,
$$

where $\sigma_{2}>0$.

Here, (27) becomes negative semidefinite and $\dot{V}_{l p f}$ does not contain any trajectories of error states $\widetilde{z}_{1}$ and $\widetilde{z}_{2}$ other than trivial trajectory $\widetilde{z}_{1}=\widetilde{z}_{2}=0$. Then, error states $\widetilde{z}_{1}$ and $\widetilde{z}_{2}$ converge asymptotically to zero. Hence, the system given by (15) and (16) with control law $u_{r}$ given in (26) is asymptotically stable.
In Section 3, the airflow control concept would be extended to the airflow control of OWC-OEN. As per the analysis of this work, the formation of OWC-OEN reduces the OPV as compared to the individual OWC plant. This could be further reduced by a centralized airflow controller to restrict the power generation as per the desired or reference power. The power output signal is sent by communication network to the controller. The controller output is again sent back to the OWC using the same channel. Needless to mention that the communication channel is a digital platform wherein the analog-to-digital (A/D) and digital-to-analog conversion (D/A) of plant and controller data also takes place simultaneously.

\section{Formation of OWC-OEN and Centralized Airflow Controller Design}

In this section, the concept depicted in Figure 1 is extended to a network of multiple OWC sites at different geographical locations.

3.1. Formation of OWC-OEN. The OWC-OEN is proposed to be implemented in a smaller coastal region not greater than $50 \mathrm{~km}$. OWC sites of OWC-OEN are independent from each other and are having at least $2 \mathrm{~km}$ distance between them. Typically, the distance covered by the wave front is a few hundred meters. As per the proposed configuration, two sites are separated by at least two kilometers and thus, the wave profiles at these two sites can be assumed to be uncorrelated. Next, each OWC site receives distinct sea wave input due to changed geographical location.

It is also assumed that each OWC site of OWC-OEN supplies the current to a common electrical grid, as shown in Figure 5, wherein the grid voltage and frequency are assumed to be constant. Hence, the total output power could be taken as a sum of output power of all individual OWC sites provided there is common grid voltage provided to each OWC. Suppose, there are $N$ number of OWC sites connected to the grid network and are called as OWC-1, OWC-2,..., OWC-N. The output power from these OWC sites is denoted as $P_{g 1}, P_{g 2}, \ldots, P_{g N}$. The total output power, $P_{\text {gtotal }}$, is given as follows:

$$
P_{\text {gtotal }}=\sum_{k=1}^{N} P_{g k}=\sum_{k=1}^{N} T_{e k} \omega_{r k}=\sum_{k=1}^{N} V_{s k} I_{s k},
$$

where $T_{e k}$ is the electromagnetic torque of $k$ th OWC site; $\omega_{r k}$ is the rotor speed of $k$ th OWC site; $V_{s k}$ is the grid voltage of $k$ th OWC site and $V_{s 1}=V_{s 2}=\cdots=V_{s N}$; and $I_{s k}$ is the current supplied by $k$ th OWC site to grid and $I_{s 1} \neq I_{s 2} \neq \cdots \neq I_{s N}$.

The centralized airflow control unit, as displayed by Figure 5, is located in the land area and is not very far (few tens of kilometers) from different OWC sites of OWC-OEN. Each OWC site is also equipped with MPPT control at a local level so as to extract maximized output power. We consider the use of high speed fiber-optic cables for communication between the central airflow control unit and the OWC-OEN. 


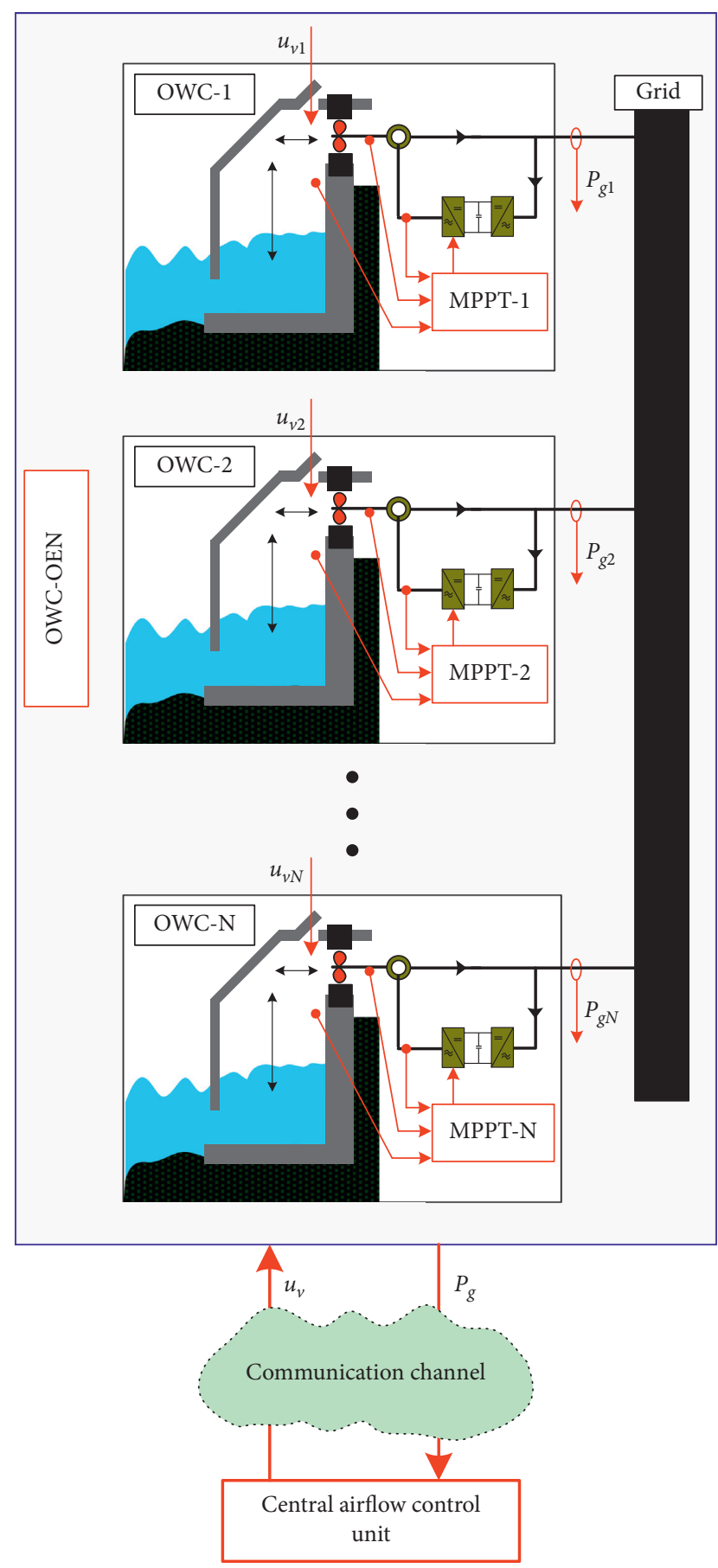

FIGURE 5: Block diagram of OWC-OEN and its centralized control unit.

The output power data from OWC sites is transmitted to the controller and vice versa. The one-way delay time associated with fiber-optic cables for communication over large distances (several hundreds of kilometers) is typically around $100-150 \mathrm{~ms}$ [49]. As the distance between the central control unit and the OWC sites is only a few tens of kilometers, the communication delay would be much lower than $100 \mathrm{~ms}$. In order to ensure a rigorous analysis of simulation results, three communication delays on higher side are considered as $\tau=100 \mathrm{~ms}, 500 \mathrm{~ms}$, and $1000 \mathrm{~ms}$.
Three types of configurations of OWC-OEN from the control point of view are considered in this study which are uncontrolled, localized MPPT control, and centralized airflow control. In uncontrolled configuration, the controllers are assumed to be absent at local (i.e., MPPT control) as well as central level (i.e., airflow control). Therefore, the output power of each OWC site is delivered to the grid without performing any control action. In localized MPPT control of OWC-OEN, each OWC site is coupled with MPPT control at the local level and the maximized power is extracted. Then, the maximized output power from each OWC site is delivered to the grid. In centralized airflow control of OWCOEN, each OWC site is integrated with control valves. The control valves are operated at the central level using the airflow controller that controls the amount of total power delivered to the grid.

3.2. Centralized Airflow Controller Structure. The internal structure of central airflow control unit of OWC-OEN is shown in Figure 6. It consists of two control stages as control stage- 1 and control stage- 2 . Control stage- 1 consists of a PItype controller. The total output power, $P_{g \text { total }}$, is compared with the reference total output power, $P_{\text {gtotal-ref }}$, and error, $e_{\text {gtotal }}$, is fed to the PI controller. The PI controller provides a common control command $P_{g-\text { ref }}$ to control stage-2. The internal structure of antiwindup PID-type controllers used for control stage-2 is shown in Figure 7.

The error $e_{g k}(t)$ in Figure 7 is given as follows:

$$
e_{g k}(t)=P_{g-r e f}-P_{g k},
$$

where $k=1,2, \ldots, N . P_{g-\text { ref }}$ is the common reference command obtained from the central PI controller as depicted in Figure 6 and $P_{g k}$ is the output power obtained from $k$ th OWC site via communication network. The suffix $k$ is used to denote the $\mathrm{PID}_{k}$ controller that belongs to $k$ th OWC site. Similarly, $K_{p k}, T_{i k}$, and $T_{d k}$ are the proportional gain, integral time constant, and derivative time constant of the $\mathrm{PID}_{k}$, respectively. Next, the output of $\mathrm{PID}_{k}$ controller, $u_{v k}$, works as the input to the airflow control valve of $k$ th OWC site. Antiwindup PID controller output characterises the effective valve area. Therefore, the effective turbine duct area fluctuates according to the deviations in the valve area, and the required output power is achieved by adjusting the air flow rate. For simplicity, the transfer ratio between the valve input (control signal) and the valve output was taken as unity. The saturation effect is due to the valve that works as the final control actuator. Therefore, the PID output is constrained to prevent the impact of valve saturation. The saturation range is taken between 0 and 1 . The PID output has no effect on the valve reaction when the valve becomes saturated. The valve goes to a steady state, but the error between the actual and desired values causes the amplitude of the PID integrator to increase continuously. It enhances the control effort without affecting the valve response. To avoid this, the antiwindup PID control scheme has been implemented wherein the integral action of PID is reduced via algebraic feedback, as shown in Figure 7. The antiwindup 


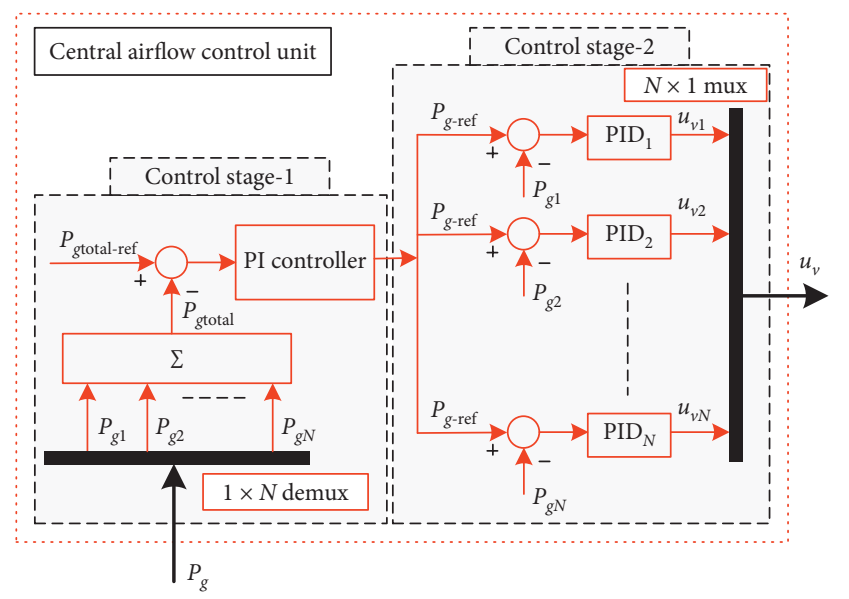

FIGURE 6: Block diagram of internal structure of central control unit.

PID controller scheme was also proposed earlier in [23, 24] for the OWC plant.

3.3. OPV Index of Individual OWC Sites and OWC-OEN. The OPV index is the difference between the maximum and minimum values of the actual output power of OWC divided by the total rated power of the OWC. The main objective of this paper is to reduce the deviations in the output power to make it suitable for electrical grid integration. In other words, the OPV index is the measurement of the suitability of the output power for the electrical grid, and it is desirable to keep this index as minimum as possible. Next, we define an OPV index as follows:

$$
\mathrm{OPV}=\left|\frac{P_{g-\text { max }}-P_{g-\min }}{P_{g-\text { rated }}}\right|,
$$

where $P_{g-\max }$ and $P_{g-\min }$ are the maximum and minimum values of output power of an OWC, respectively.

Now, for individual OWC sites, the OPV index is defined as follows:

$$
\left.\begin{array}{l}
\mathrm{OPV}_{1}=\left|\frac{P_{g 1-\text { max }}-P_{g 1-\text { min }}}{P_{g 1-\text { rated }}}\right| \\
\mathrm{OPV}_{2}=\left|\frac{P_{g 2-\text { max }}-P_{g 2-\text { min }}}{P_{g 2 \text {-rated }}}\right| \\
\cdot \\
\cdot \\
\mathrm{OPV}_{N}=\left|\frac{P_{g N-\text { max }}-P_{g N-\text { min }}}{P_{g N-\text { rated }}}\right|
\end{array}\right\}
$$

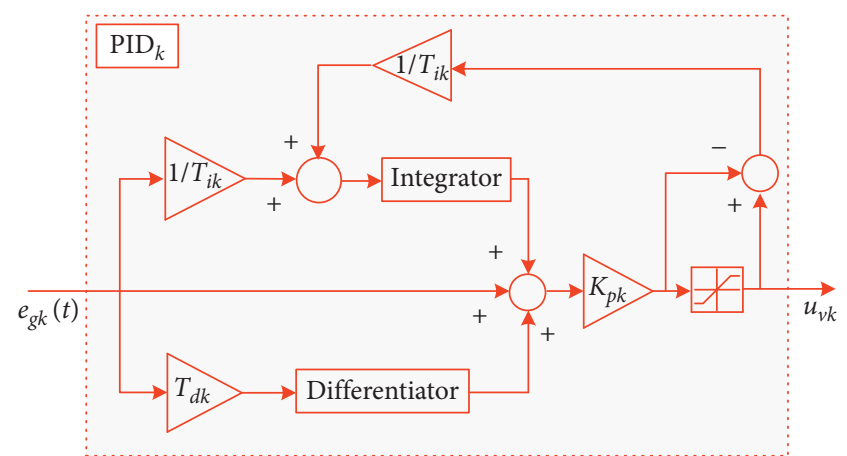

Figure 7: Antiwindup PID controller structure of $k$ th OWC site.

Next, the OPV for complete OWC-OEN is defined as follows:

$$
\mathrm{OPV}_{\text {total }}=\left|\frac{P_{g \text { total }- \text { max }}-P_{\text {gtotal-min }}}{P_{\text {gtotal-rated }}}\right|,
$$

where $P_{g k \text {-rated }}$ is the rated power of the $k$ th OWC site and $P_{g \text { total-rated }}$ is the rated power of OWC-OEN.

The OPV index expressed in (10), (11), and (12) is very important for measuring the improvement in the power variation of OWC-OEN. The objective is to obtain the minimum possible value of OPV index by suitably designing the centralized airflow controller.

3.4. Centralized Airflow Controller Tuning Using PSO. The complex controller tuning involves $3 N+2$ unknown parameters to be determined. Therefore, we choose PSObased optimization approach for tuning controller parameters. Now, we define an ISE type fitness function as follows:

$$
\text { ISE }=\int_{0}^{T_{s}} e_{g \text { total }}^{2} \mathrm{~d} t
$$

where $e_{\text {gtotal }}$ is defined as follows:

$$
e_{\text {gtotal }}=P_{\text {gtotal }- \text { ref }}-P_{\text {gtotal }} .
$$

Therefore, the ISE can be written as follows:

$$
\text { ISE }=\int_{0}^{T_{s}}\left(P_{g \text { total }- \text { ref }}-P_{g \text { total }}\right)^{2} \mathrm{~d} t
$$

where $T_{s}$ is simulation run time of the OWC-OEN model.

Next, the objective is to minimize ISE in such a way that all $3 N+2$ parameters of OWC-OEN controllers are properly selected. So, the PSO algorithm has been applied for optimum selection of control parameters of OWC-OEN.

The population-based swarm intelligence method is widely adopted to find the optimal solution when solving complex optimization problems with a large search area. The PSO approach $[39,40]$ is a population-dependent search strategy that has a wide target field to address the problem of optimization. This approach represents the behavior of birds and fish schools. In a PSO system, an individual bird or fish is known as particles and each particle has its position and velocity. Now, particle travels in multidimensional search space depending on its own knowledge and the surrounding 
particle experience. The position and speed of the particles are changed during the search space movement. The velocity and position upgrading of particles depends on three factors which are inertia, cognitive, and social factors.

The PSO is a very popular as well simple approach for tuning PID controllers. Several research studies have applied PSO in their works related to PID controller tuning [41, 42]. However, there are many optimization algorithms available in the literature and anyone of them could be utilized for tuning purpose. The comparison of optimization algorithms is not taken into account in this study because the proposed research work is mainly focused on reduction in OPV using centralized airflow controller.

The velocity and position update of each particle can be calculated using the current velocity and position as follows:

$$
\begin{aligned}
V_{j}^{k+1}= & W V_{j}^{k}+c_{p 1} \times \operatorname{rand}() \times\left[p_{\text {best }, j}-X_{j}^{k}\right]+c_{p 2} \times \operatorname{rand}() \\
& \left.\times\left[g_{\text {best }, j}-X_{j}^{k}\right]\right\} .
\end{aligned}
$$

Position update equation is given by

$$
X_{j}^{k+1}=X_{j}^{k}+V_{j}^{k+1},
$$

where

$$
W_{p}=W_{p-\max }-\left[W_{p-\max }-W_{p-\min }\right] \times\left(\frac{k_{\max }}{k}\right),
$$

and $k_{p \text {-max }}=$ maximum number of iterations, $k=$ iteration number, $j=$ particle number, $V_{j}^{k}=$ velocity of $j$ th particle in $k$ th iteration, $W_{p}=$ inertia weight factor, $W_{p-\max }=$ Maximum inertia weight factor, $W_{p-\min }=$ Minimum inertia weight factor, $c_{p 1}=$ cognitive acceleration factor, $c_{p 2}=$ social acceleration factor, rand ()$=$ random numbers uniformly distributed in the range $(0,1), X_{j}^{k}=$ position of $j$ th particle in $k$ th iteration, $p_{\text {best }}=$ local best position, and $g_{\text {best }}=$ global best position. The block diagram of PSO algorithmbased tuning of OWC-OEN controllers is given in Figure 8.

\section{Discussion on Simulation Results}

In this section, the centralized airflow controller has been validated through numerical simulations. The simulation parameters used for OWC-OEN airflow control and rotor speed regulation schemes are provided in Table 1. The number of OWC sites are chosen to be $N=20$. The WAFO toolbox in $\mathrm{MATLAB}^{\circledR}$ has been used for generating JONSWAP spectrum-based twenty distinct sea wave scenarios for twenty OWC sites located at different locations.

The sea scenario $S W 1$ (Figure 9) is chosen for demonstrating the MPPT outcome of $O W C-1$, whereas all sea scenarios, i.e., $S W 1, S W 2, \ldots, S W 20$, are selected for evaluating the performance of OWC-OEN with MPPT, uncontrolled OWC-OEN, and OWC-OEN with centralized airflow control. The wave height and corresponding airflow velocity for sea scenario, $S W 1$, is shown in Figure 9.

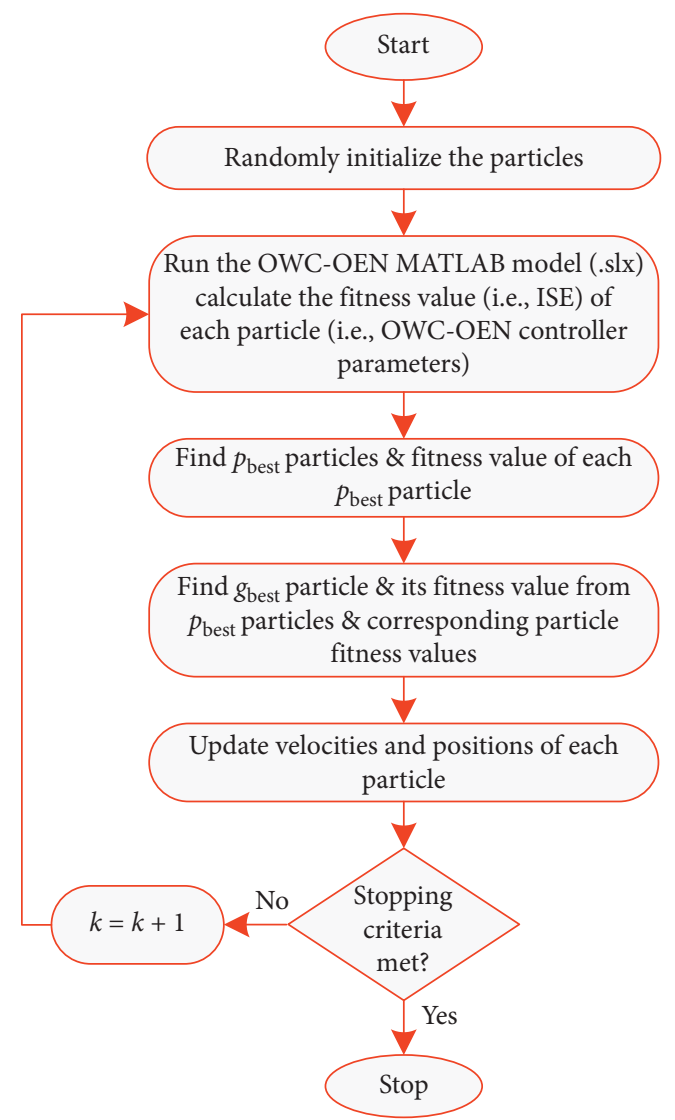

FIgURE 8: PSO algorithm flowchart for tuning OWC-OEN controller parameters.

4.1. Performance Analysis of MPPT Control. The MPPT performance of OWC-1 at the local level has been evaluated in this section. The optimum reference speed, $\omega_{\text {ref-OwC1 }}$, is calculated first using the algorithm suggested in [36]. This reference is generated in a manner that the turbine flow coefficient always remains below the permissible threshold limit to escape the turbine stalling. If turbine stalling is avoided, then the output power can be maximized to its best possible level. Next, the backstepping-based nonlinear controller is implemented for rotor speed control that in turn provides the efficient tracking of reference speed by actual rotor speed. This is observed in Figure 10, wherein the actual rotor speed of OWC-1 very closely follows the optimum reference speed. The rotor speed for uncontrolled OWC-1 is clearly representing the turbine stalling case. The control effort needed to manipulate the rotor speed is also shown in Figure 10 which is having a range of \pm 150 volts and is required only when the reference value is changing.

Next, turbine flow coefficient and electrical power waveforms are shown by Figure 11. The turbine flow coefficient for MPPT-controlled OWC-1 always remains below the threshold level, i.e., 0.3 , whereas for uncontrolled OWC1 , it exceeds the threshold and causes the stalling in Wells turbine. Similarly, the output power gets maximized in case of MPPT control as compared to uncontrolled OWC-1. However, the OPV is very high as seen in power waveform for OWC-1. The OPV index of all OWC units is provided in 

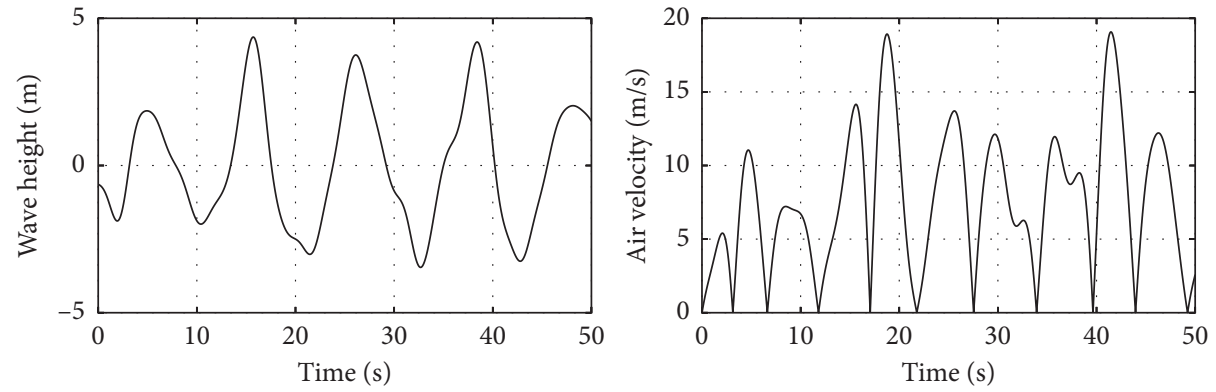

FIGURE 9: Wave height and corresponding airflow velocity (absolute) for OWC-1 with SW1.
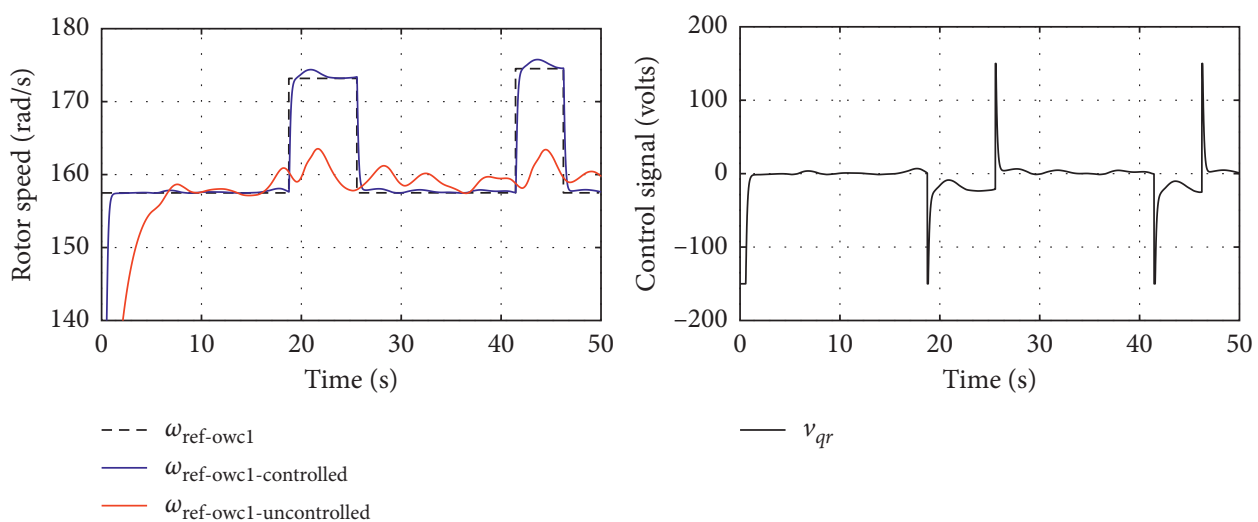

FIgURE 10: Rotor speed and control signal for OWC-1 with SW1.
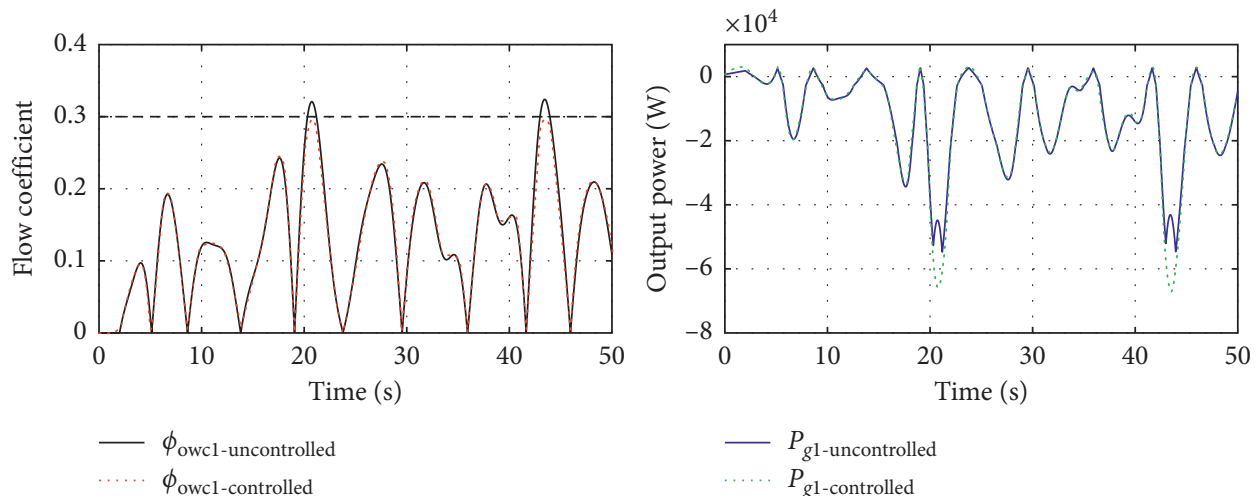

FIgURE 11: Flow coefficient and output power for OWC-1 with $S W 1$.

Table 2 which would be compared with the OPV index of OWC-OEN later.

As shown in Figure 12, the total output power has been analyzed with and without MPPT control after forming OWC-OEN. For uncontrolled case, the output power obtained has a peak value of $P_{\text {gtotal-max }}=-373.3 \mathrm{~kW}$, whereas MPPT control provides the peak value of $P_{\text {gtotal-max }}=-587.4 \mathrm{~kW}$. Again, the OPV index of OWCOEN is not at an acceptable level. Therefore, the centralized airflow controller to be discussed next was required to deal with high OPV issue of OWC-OEN.

The output power waveforms have negative amplitude which represents the generation mode of DFIG. In the generation mode, the negative peak of output power actually represents the $P_{g-\max }$. The value of output power that is close to time axis is treated as $P_{g-\min }$. In the motor mode of DFIG, the power waveforms would have positive amplitude.

\subsection{Performance Analysis of Centralized Airflow Control.} The centralized airflow controller, as shown in Figure 6, is designed using PSO. For $N=20$, there are 62 control parameters which have been tuned with an objective to minimize the ISE as given in (35). The ISE was minimized by applying PSO algorithm as per the flowchart shown in Figure 8. The PSO parameters for running optimization are given in Table 3. 
TABLE 2: OPV index values of individual OWC sites.

\begin{tabular}{lccc}
\hline OWC site & $P_{g-\min }(\mathrm{kW})$ & $P_{g-\max }(\mathrm{kW})$ & OPV index \\
\hline OWC-1 & 2.6 & -53.2 & 0.558 \\
OWC-2 & 2.5 & -54.5 & 0.570 \\
OWC-3 & 2.5 & -31.6 & 0.341 \\
OWC-4 & 2.6 & -55.2 & 0.578 \\
OWC-5 & 2.7 & -54.4 & 0.571 \\
OWC-6 & 2.6 & -54.1 & 0.567 \\
OWC-7 & 2.6 & -54.0 & 0.566 \\
OWC-8 & 2.7 & -48.6 & 0.513 \\
OWC-9 & 2.6 & -51.5 & 0.541 \\
OWC-10 & 2.7 & -54.6 & 0.573 \\
OWC-11 & 2.6 & -40.1 & 0.427 \\
OWC-12 & 2.6 & -53.5 & 0.561 \\
OWC-13 & 2.7 & -47.7 \\
OWC-14 & 2.7 & -54.5 & 0.504 \\
OWC-15 & 2.7 & -54.8 & 0.572 \\
OWC-16 & 2.7 & -54.3 & 0.575 \\
OWC-17 & 2.7 & -54.8 & 0.570 \\
OWC-18 & 2.7 & -48.6 & 0.575 \\
OWC-19 & 2.7 & -52.2 & 0.513 \\
OWC-20 & 2.7 & -54.6 & 0.549 \\
\hline
\end{tabular}
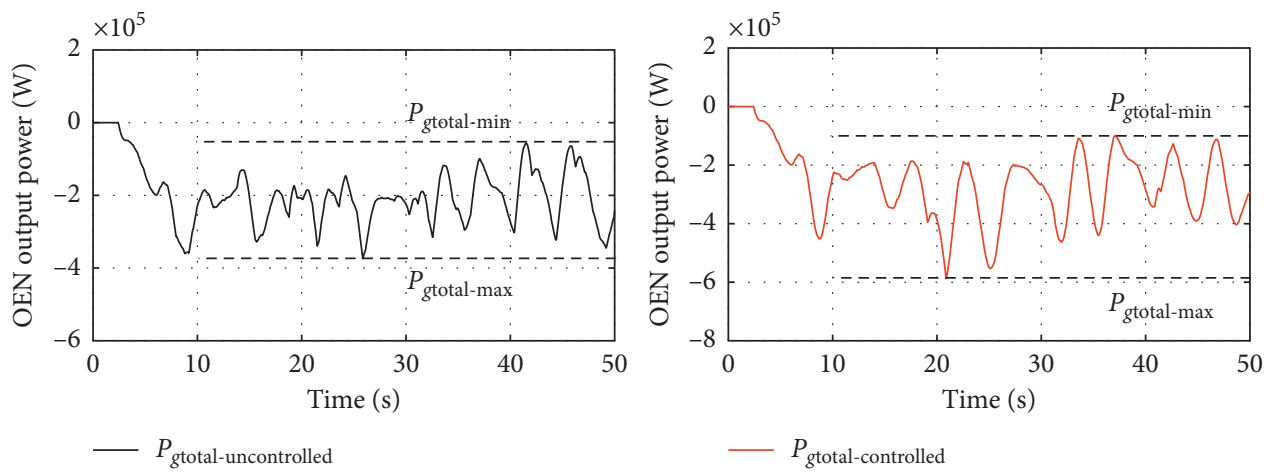

FIGURE 12: Total output power for uncontrolled and MPPT-controlled OWC-OEN.

Next, the optimized control parameters were obtained by running the optimization algorithm for 100 iterations. The tuned parameters of centralized airflow controller are provided in Table 4 . The numerical simulations are obtained for OWC-OEN with a centralized airflow controller. Three cases of total output power reference (i) $P_{\text {gtotal-ref }}=-50 \mathrm{~kW}$, (ii) $P_{g \text { total-ref }}=-110 \mathrm{~kW}$, and (iii) $P_{g \text { total-ref }}=-200 \mathrm{~kW}$ have been considered for analyzing the controller performance. The $P_{\text {gtotal-ref }}$ selection is based on observing the total output power waveforms. The total output power is more concentrated in the lower range (i.e., below $-250 \mathrm{~kW}$ ) and hence, the centralized airflow controller is found to be more effective in the lower range and the effectiveness gets reduced substantially at higher ranges.

The total output power, $P_{g \text { total }}$, and corresponding error waveforms for different references are shown in Figure 13. The total output power of OWC-OEN successfully tracks the reference power. Although for lower as well as higher $P_{\text {gtotal-ref }}$, the OPV index is higher when compared with $P_{\text {gtotal-ref }}=-110 \mathrm{~kW}$. The lowest OPV index of 0.0093 is achieved with $P_{g \text { total-ref }}=-110 \mathrm{~kW}$. Overall, the airflow
TABLE 3: PSO parameters.

\begin{tabular}{lc}
\hline PSO parameters & Values \\
\hline Number of particles & 50 \\
Particle dimension & 62 \\
Maximum number of iteration $\left(k_{p-\max }\right)$ & 100 \\
Maximum inertia weight factor $\left(W_{p-\text { max }}\right)$ & 0.9 \\
Minimum inertia weight factor $\left(W_{p-\min }\right)$ & 0.1 \\
Cognitive acceleration factor $\left(c_{p 1}\right)$ & 2 \\
Social acceleration factor $\left(c_{p 2}\right)$ & 2 \\
\hline
\end{tabular}

controller reduces the OPV significantly as compared to uncontrolled OWC-OEN and MPPT-controlled OWCOEN. Next, a detailed comparison of OPV index values for uncontrolled OWC-OEN, MPPT-controlled OWC-OEN, and OWC-OEN with centralized airflow controller can be found in Table 5. It can be seen in the table that the centralized airflow controller leads to lowest OPV index among all configurations of OWC-OEN. The OPV index with MPPT controlled OWC-OEN is higher than that of uncontrolled OWC-OEN as provided in Table 5. The 
TABLE 4: Central airflow control unit parameters.

\begin{tabular}{|c|c|c|c|c|}
\hline Controllers & & $K_{p}$ & $T_{i}$ & $T_{d}$ \\
\hline \multirow{10}{*}{ Control Stage-1 } & PI & 0.130 & 0.129 & - \\
\hline & $\mathrm{PID}_{1}$ & 8.580 & 2.078 & 1.131 \\
\hline & $\mathrm{PID}_{2}$ & 5.850 & 0.617 & 0.642 \\
\hline & $\mathrm{PID}_{3}$ & 9.765 & 1.278 & 1.989 \\
\hline & $\mathrm{PID}_{4}$ & 6.905 & 2.155 & 0.988 \\
\hline & $\mathrm{PID}_{5}$ & 11.528 & 2.092 & 1.734 \\
\hline & $\mathrm{PID}_{6}$ & 6.121 & 0.806 & 2.376 \\
\hline & $\mathrm{PID}_{7}$ & 5.254 & 2.329 & 1.096 \\
\hline & $\mathrm{PID}_{8}$ & 11.191 & 2.029 & 1.856 \\
\hline & $\mathrm{PID}_{9}$ & 7.240 & 2.025 & 2.764 \\
\hline \multirow{11}{*}{ Control Stage-2 } & $\mathrm{PID}_{10}$ & 5.915 & 2.427 & 0.917 \\
\hline & $\mathrm{PID}_{11}$ & 3.321 & 1.639 & 1.970 \\
\hline & $\mathrm{PID}_{12}$ & 11.860 & 2.197 & 0.804 \\
\hline & $\mathrm{PID}_{13}$ & 7.070 & 2.449 & 0.917 \\
\hline & $\mathrm{PID}_{14}$ & 10.458 & 1.816 & 2.093 \\
\hline & $\mathrm{PID}_{15}$ & 5.011 & 2.642 & 1.617 \\
\hline & $\mathrm{PID}_{16}$ & 10.403 & 1.945 & 1.140 \\
\hline & $\mathrm{PID}_{17}$ & 8.131 & 2.460 & 0.858 \\
\hline & $\mathrm{PID}_{18}$ & 10.751 & 0.735 & 1.860 \\
\hline & $\mathrm{PID}_{19}$ & 10.293 & 2.499 & 0.767 \\
\hline & $\mathrm{PID}_{20}$ & 6.380 & 1.150 & 0.912 \\
\hline
\end{tabular}
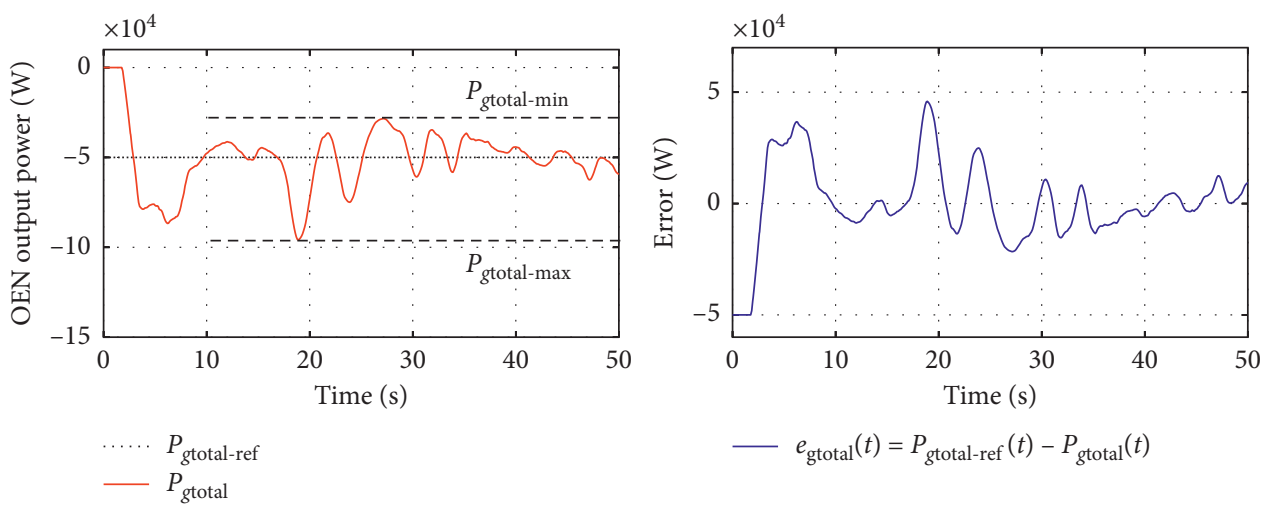

(a)
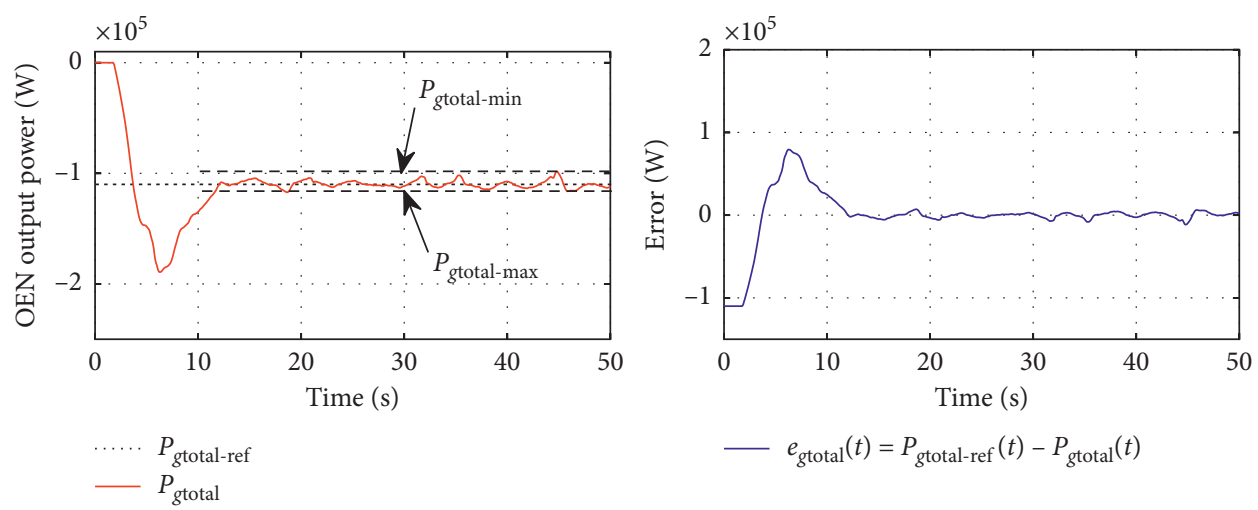

(b)

Figure 13: Continued. 

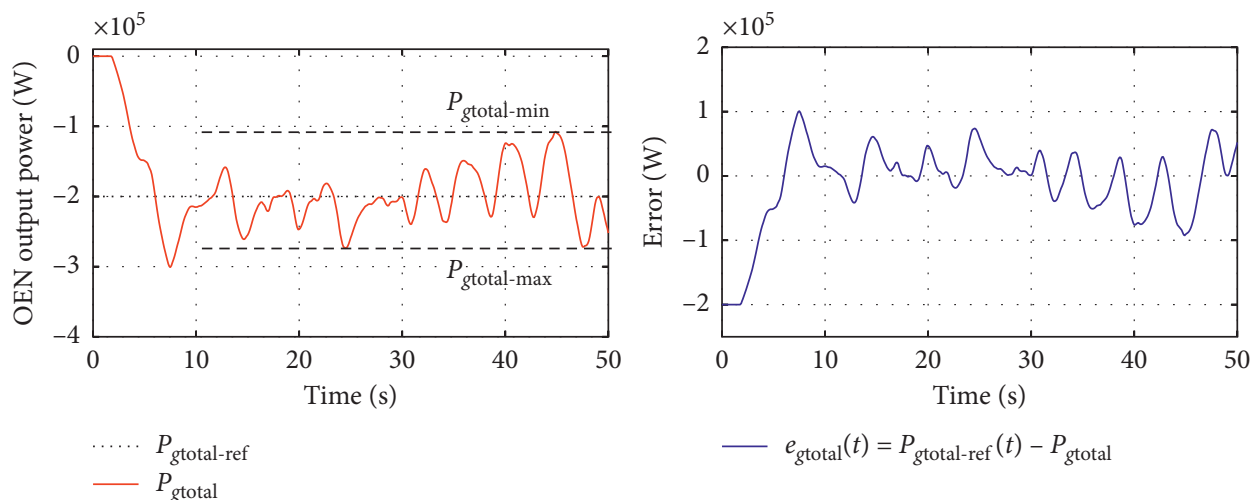

(c)

Figure 13: OWC-OEN output power and error waveforms with centralized airflow controller. (a) $P_{\text {gtotal-ref }}=-50 \mathrm{~kW}$, (b) $P_{\text {gtotal-ref }}=-110 \mathrm{~kW}$, and (c) $P_{\text {gtotal-ref }}=-200 \mathrm{~kW}$.

TABLE 5: OPV index values of OWC-OEN.

\begin{tabular}{|c|c|c|c|c|}
\hline \multicolumn{2}{|l|}{ OWC-OEN } & $P_{g-\min }(\mathrm{kW})$ & $P_{g-\max }(\mathrm{kW})$ & OPV index \\
\hline \multirow{2}{*}{\multicolumn{2}{|c|}{$\begin{array}{l}\text { Uncontrolled } \\
\text { MPPT }\end{array}$}} & -56.6 & -373.3 & 0.1583 \\
\hline & & -56.2 & -587.4 & 0.2656 \\
\hline \multirow{4}{*}{ Airflow control } & $P_{\text {gtotal-ref }}=110 \mathrm{~kW}$ & -98.5 & -117.1 & 0.0093 \\
\hline & $P_{\text {gtotal-ref }}=50 \mathrm{~kW}$ & -28.4 & -96.0 & 0.0338 \\
\hline & $P_{\text {gtotal-ref }}^{\text {glotal-ref }}=200 \mathrm{~kW}$ & -107.5 & -273.9 & 0.0832 \\
\hline & $\tau=100 \mathrm{~ms}$ & -98.1 & -118.7 & 0.0103 \\
\hline \multirow{2}{*}{ Airflow control with delay } & $\tau=500 \mathrm{~ms}$ & -65.0 & -175.2 & 0.0551 \\
\hline & $\tau=1000 \mathrm{~ms}$ & -50.0 & -201.5 & 0.0757 \\
\hline
\end{tabular}
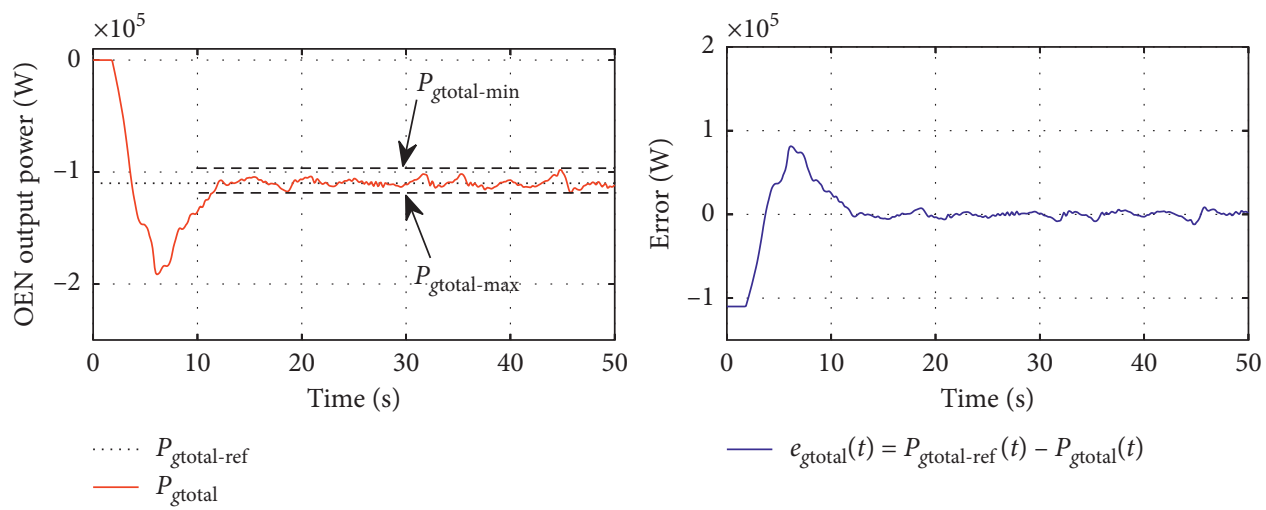

(a)
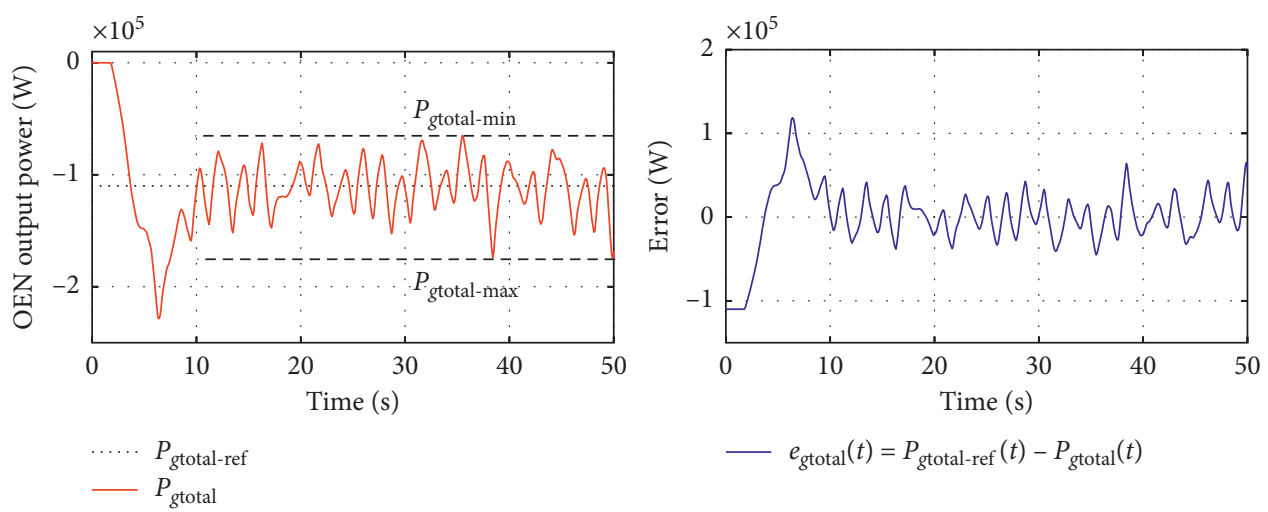

(b)

Figure 14: Continued. 

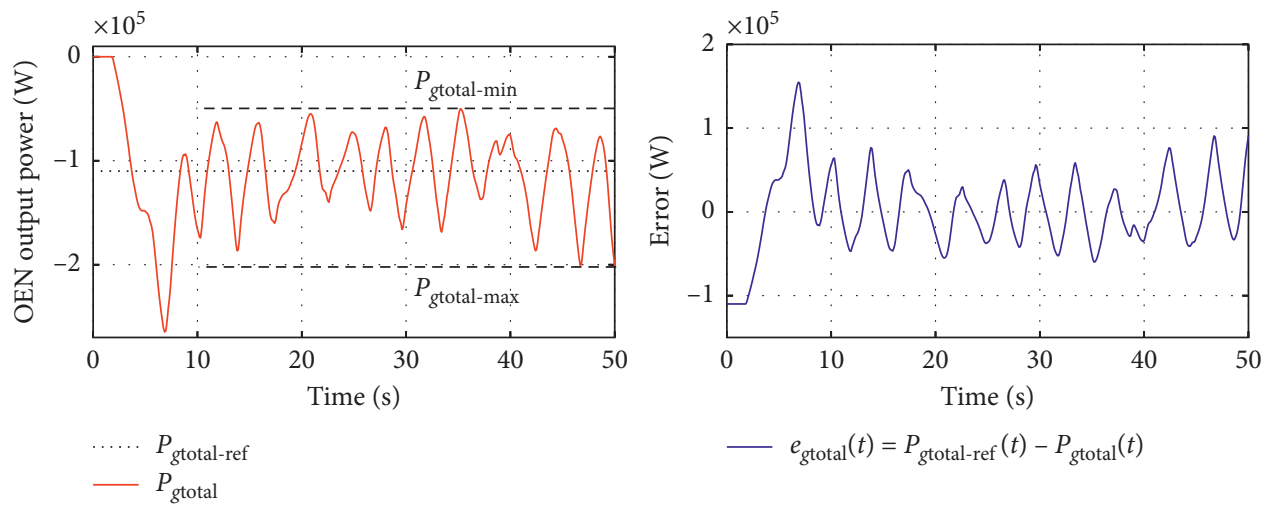

(c)

FIgURE 14: OEN output power and error waveforms with communication delay. (a) $\tau=100 \mathrm{~ms}$. (b) $\tau=500 \mathrm{~ms}$. (c) $\tau=1000 \mathrm{~ms}$.

centralized airflow controller is also tested with different cases of communication delay in OWC-OEN in next section.

\subsection{Performance Analysis of Centralized Airflow Control with} Communication Delay. The centralized airflow controller has been validated with different communication delays of $\tau=100 \mathrm{~ms}, 500 \mathrm{~ms}$, and $1000 \mathrm{~ms}$. The total output power and corresponding error waveforms are shown in Figure 14. The OPV index increases with increase in $\tau$ value as observed from the waveforms. So, it is required that the communication network should be able to transfer data with a very high speed in order to avoid any performance deterioration occurring due to delay. However, it is very much possible nowadays to transmit data with bandwidths in gigahertz range with advanced communication technology. It is also to be noted here that each OWC site may have different communication delays which needs further attention. It is observed that the total output power waveform in Figure 14(a) seems very similar to that of Figure 13(b) with $P_{\text {gtotal-ref }}=-110 \mathrm{~kW}$. It is due to the time range of $40 \mathrm{~s}$ in both Figures 14(a) and 13(b) which is very high as compared to the communication delay of $100 \mathrm{~ms}$. Therefore, the variation appears in the same Figures 14(a) and 13(b). However, there is clear difference in performance of both ceases in terms of the OPV index, as given in Table 5.

\section{Concluding Remarks and Future Challenges}

This paper presented a novel concept of OWC-OEN and its centralized airflow control to mitigate the OPV issue of ocean energy systems. The centralized airflow controller consisting of two control stages was designed using PSO due to complexity of tuning parameters. The PSO helped in choosing large number of control parameters of a very complex OWC-OEN by minimizing an ISE-type fitness function. A comprehensive simulation analysis was presented to validate the proposed airflow control scheme. The JOWNSWAP-based irregular wave patterns were randomly selected as the input to individual OWC sites. Also, an OPV index was defined to compare the output power waveforms of individual OWC sites and OWC-OEN. The OWC-OEN with centralized airflow control delivers the lowest OPV index as compared to uncontrolled OWC-OEN and MPPT controlled OWC-OEN. The centralized airflow controller works reasonably well when OWC-OEN is under the effect of communication delay. As with the case of any other spatially distributed control network, large communication delays degrade the performance of the OWC-OEN. The communication delays considered in this study are assumed to be uniform for all OWC sites. The unequal communication delays for OWC sites located at different geographical locations would further increase the complexity of OWCOEN. It is an interesting subject, which needs thorough investigation in further studies on OWC-OEN.

\section{Data Availability}

All the data are included within the article. Additional data can be provided by the corresponding author upon request (sunil.mishrafet@kiit.ac.in).

\section{Conflicts of Interest}

The authors declare that they have no conflicts of interest.

\section{Acknowledgments}

This work was supported in part by the Basque Government through project IT1207-19 and MCIU/MINECO through RTI2018-094902-B-C21/RTI2018-094902-B-C22 (MCIU/AEI/ FEDER, UE).

\section{References}

[1] D. Magagna and A. Uihlein, "Ocean energy development in Europe: current status and future perspectives," International Journal of Marine Energy, vol. 11, pp. 84-104, 2015.

[2] A. M. O’Hagan, C. Huertas, J. O'Callaghan, and D. Greaves, "Wave energy in Europe: views on experiences and progress to date," International Journal of Marine Energy, vol. 14, pp. 180-197, 2016.

[3] V. Stratigaki, "WECANet: the first open pan-European network for marine renewable energy with a focus on wave 
energy-COST action CA17105," Water, vol. 11, no. 6, p. 1249 , 2019.

[4] G. Hennequin, "Hydro, tidal and wave energy in Japanbusiness, research and technological opportunities for European companies," Minerva Fellowship, Tokyo, Japan, 2016.

[5] M. Lehmann, F. Karimpour, C. A. Goudey, P. T. Jacobson, and M.-R. Alam, "Ocean wave energy in the United States: current status and future perspectives," Renewable and Sustainable Energy Reviews, vol. 74, pp. 1300-1313, 2017.

[6] D. Khojasteh, S. M. Mousavi, W. Glamore, and G. Iglesias, "Wave energy status in Asia," Ocean Engineering, vol. 169, pp. 344-358, 2018.

[7] S. Qiu, K. Liu, D. Wang, J. Ye, and F. Liang, "A comprehensive review of ocean wave energy research and development in China," Renewable and Sustainable Energy Reviews, vol. 113, p. 109271, 2019.

[8] A. Schiller, G. B. Brassington, P. Oke et al., "Bluelink ocean forecasting Australia: 15 years of operational ocean service delivery with societal, economic and environmental benefits," Journal of Operational Oceanography, vol. 13, no. 1, pp. 1-18, 2020.

[9] M. Shadman, C. Silva, D. Faller et al., "Ocean renewable energy potential, technology, and deployments: a case study of Brazil," Energies, vol. 12, no. 19, p. 3658, 2019.

[10] K. Freeman, M. Dai, and R. Sutton, "Control strategies for oscillating water column wave energy converters," Underwater Technology: International Journal of the Society for Underwater, vol. 32, no. 1, pp. 3-13, 2014.

[11] A. F. O. Falcão and J. C. C. Henriques, "Oscillating-watercolumn wave energy converters and air turbines: a review," Renewable Energy, vol. 85, pp. 1391-1424, 2016.

[12] N. Delmonte, D. Barater, F. Giuliani, P. Cova, and G. Buticchi, "Review of oscillating water column converters," IEEE Transactions on Industry Applications, vol. 52, no. 2, pp. 1698-1710, 2015.

[13] R. E. Hoskin, B. M. Count, N. K. Nichols, and D. A. C. Nicol, "Phase control for the oscillating water column," Hydrodynamics of Ocean Wave-Energy Utilization, Springer, Berlin, Germany, pp. 257-268, 1986.

[14] R. Jefferys and T. Whittaker, "Latching control of an oscillating water column device with air compressibility," $\mathrm{Hy}$ drodynamics of Ocean Wave-Energy Utilization, Springer, Berlin, Germany, pp. 281-291, 1986.

[15] L. M. C. Gato and A. F. d. O. Falcao, "Aerodynamics of the wells turbine: control by swinging rotor-blades," International Journal of Mechanical Sciences, vol. 31, no. 6, pp. 425-434, 1989.

[16] U. A. Korde, "Development of a reactive control apparatus for a fixed two-dimensional oscillating water column wave energy device," Ocean Engineering, vol. 18, no. 5, pp. 465-483, 1991.

[17] A. F. d. O. Falcao and P. A. P. Justino, "OWC wave energy devices with air flow control," Ocean Engineering, vol. 26, no. 12 , pp. 1275-1295, 1999.

[18] P. A. P. Justino and A. F. d. O. Falcao, "Rotational speed control of an OWC wave power plant," Journal of Offshore Mechanics and Arctic Engineering, vol. 121, no. 2, pp. 65-70, 1999.

[19] V. Jayashankar, K. Udayakumar, B. Karthikeyan, K. Manivannan, N. Venkatraman, and S. Rangaprasad, "Maximizing power output from a wave energy plant," in Proceedings of the IEEE Power Engineering Society Winter Meeting, vol. 3, pp. 1796-1801, Singapore, January 2000.

[20] S. S. Rao and B. K. Murthy, "Control of induction generator in a wells turbine based wave energy system," in Proceedings of the IEEE International Conference on Power Electronics and Drives Systems, vol. 2, pp. 1590-1594, Kuala Lumpur, Malaysia, November 2005.

[21] B. K. Murthy and S. Srinivasa Rao, "Rotor side control of wells turbine driven variable speed constant frequency induction generator," Electric Power Components and Systems, vol. 33, no. 6, pp. 587-596, 2005.

[22] M. Amundarain, M. Alberdi, A. J. Garrido, and I. Garrido, "Neural control of the wells turbine-generator module," in Proceedings of the Joint 48th IEEE Conference on Decision and Control and 28th Chinese Control Conference, pp. 7315-7320, Shanghai, China, December 2009.

[23] M. Amundarain, M. Alberdi, A. J. Garrido, and I. Garrido, "Control strategies for OWC wave power plants," in Proceedings of the 2010 American Control Conference, pp. 43194324, Baltimore, MD, USA, June 2010.

[24] M. Amundarain, M. Alberdi, A. J. Garrido, and I. Garrido, "Modeling and simulation of wave energy generation plants: output power control," IEEE Transactions on Industrial Electronics, vol. 58, no. 1, pp. 105-117, 2011.

[25] M. Amundarain, M. Alberdi, A. J. Garrido, and I. Garrido, "Neural rotational speed control for wave energy converters," International Journal of Control, vol. 84, no. 2, pp. 293-309, 2011.

[26] M. Alberdi, M. Amundarain, A. J. Garrido, I. Garrido, and F. J. Maseda, "Fault-ride-through capability of oscillatingwater-column-based wave-power-generation plants equipped with doubly fed induction generator and airflow control," IEEE Transactions on Industrial Electronics, vol. 58, no. 5, pp. 1501-1517, 2011.

[27] A. J. Garrido, I. Garrido, M. Amundarain, M. Alberdi, and M. D. Sen, "Sliding-mode control of wave power generation plants," IEEE Transactions on Industry Applications, vol. 48, no. 6, pp. 2371-2381, 2012.

[28] S. Ceballos, J. Rea, I. Lopez, J. Pou, E. Robles, and D. L. O'Sullivan, "Efficiency optimization in low inertia wells turbine-oscillating water column devices," IEEE Transactions on Energy Conversion, vol. 28, no. 3, pp. 553-564, 2013.

[29] Y. Hong, R. Waters, C. Boström, M. Eriksson, J. Engström, and M. Leijon, "Review on electrical control strategies for wave energy converting systems," Renewable and Sustainable Energy Reviews, vol. 31, pp. 329-342, 2014.

[30] S. Ceballos, J. Rea, E. Robles, I. Lopez, J. Pou, and D. O'Sullivan, "Control strategies for combining local energy storage with wells turbine oscillating water column devices," Renewable Energy, vol. 83, pp. 1097-1109, 2015.

[31] J. Lekube, A. J. Garrido, and I. Garrido, "Rotational speed optimization in oscillating water column wave power plants based on maximum power point tracking," IEEE Transactions on Automation Science and Engineering, vol. 14, no. 2, p. 681, 2016.

[32] J. C. C. Henriques, L. M. C. Gato, A. F. O. Falcão, E. Robles, and F.-X. Faÿ, "Latching control of a floating oscillatingwater-column wave energy converter," Renewable Energy, vol. 90, pp. 229-241, 2016.

[33] S. K. Mishra, S. Purwar, and N. Kishor, "An optimal and nonlinear speed control of oscillating water column wave energy plant with wells turbine and DFIG," International Journal of Renewable Energy Research, vol. 6, no. 3, 2016.

[34] S. K. Mishra, S. Purwar, and N. Kishor, "Design of non-linear controller for ocean wave energy plant," Control Engineering Practice, vol. 56, no. 3, pp. 111-122, 2016.

[35] J. Lekube, A. Garrido, I. Garrido, E. Otaola, and J. Maseda, "Flow control in wells turbines for harnessing maximum wave power," Sensors, vol. 18, no. 2, p. 535, 2018. 
[36] S. K. Mishra, S. Purwar, and N. Kishor, "Event-triggered nonlinear control of OWC ocean wave energy plant," IEEE Transactions on Sustainable Energy, vol. 9, no. 4, pp. 17501760, 2018.

[37] F. M'zoughi, S. Bouallegue, A. J. Garrido, I. Garrido, and M. Ayadi, "Fuzzy gain scheduled PI-based airflow control of an oscillating water column in wave power generation plants," IEEE Journal of Oceanic Engineering, vol. 44, no. 4, pp. 1058-1076, 2018.

[38] F. M'zoughi, I. Garrido, A. J. Garrido, and M. De La Sen, “Selfadaptive global-best harmony search algorithm-based airflow control of a wells-turbine-based oscillating-water column," Applied Sciences, vol. 10, no. 13, p. 4628, 2020.

[39] F. M'zoughi, I. Garrido, and A. J. Garrido, "Symmetrybreaking for airflow control optimization of an oscillatingwater-column system," Symmetry (Basel).vol. 12, no. 6, p. 895, 2020.

[40] F. M'zoughi, I. Garrido, A. J. Garrido, and M. De La Sen, "ANN-based airflow control for an oscillating water column using surface elevation measurements," Sensors (Switzerland), vol. 20 , no. 5, pp. 1-21, 2020.

[41] A. Maria-Arenas, A. J. Garrido, E. Rusu, and I. Garrido, "Control strategies applied to wave energy converters: state of the art," Energies, vol. 12, no. 16, p. 3115, 2019.

[42] M. Clerc, Particle Swarm Optimization, ISTE Ltd., London, UK, 2006.

[43] R. Poli, J. Kennedy, and T. Blackwell, "Particle swarm optimization," Swarm Intelligence, vol. 1, no. 1, pp. 33-57, 2007.

[44] S. K. Mishra and D. Chandra, "Stabilization and tracking control of inverted pendulum using fractional order PID controllers," Journal of Engineering, vol. 2014, Article ID 752918, 9 pages, 2014.

[45] S. K. Mishra and S. Purwar, "To design optimally tuned FOPID controller for twin rotor MIMO system," in Proceedings of the 3rd Students Conference on Engineering and Systems (SCES), Allahabad, India, May 2014.

[46] K. Hasselmann, T. P. Bernett, E. Bouws et al., "Measurements of wind-wave growth and swell decay during the joint north sea wave project (JONSWAP)," Deutschen Hydrografischen Zeitschrift, vol. 12, pp. 31-55, 1973.

[47] P. A. Brodtkorb, G. Lindgren, I. Rychlik et al., "WAFO-a Matlab toolbox for analysis of random waves and loads," in Proceedings of the 10th International Offshore and Polar Engineering Conference, Seattle, Washington, USA, May 2000.

[48] S. Raghunathan, "The wells air turbine for wave energy conversion," Progress in Aerospace Sciences, vol. 31, no. 4, pp. 335-386, 1995.

[49] B. Nadhvathuparambil, M. C. Valenti, and A. Feliachi, "Communication delays in wide area measurement systems," in Proceedings of the Thirty-Fourth Southeastern Symposium on System Theory (Cat. No.02EX540), pp. 118-122, Huntsville, AL, USA, March 2002. 